
\title{
28 Research Square \\ The Trends and Efficacy of Operation in the Treatment of Hepatocellular Carcinoma
}

\section{Lei Chen}

Wuhan Union Hospital https://orcid.org/0000-0003-0018-9993

\section{Shi Chen}

wuhan union hospital

\section{Tao Sun}

wuhan union hospital

\section{Fan Yang}

wuhan union hospital

Chuansheng Zheng ( $\nabla$ hqzcsxh@sina.com )

https://orcid.org/0000-0002-2435-1417

\section{Research article}

Keywords: hepatocellular carcinoma, trends, operation, surgery, efficacy

Posted Date: September 16th, 2020

DOI: https://doi.org/10.21203/rs.3.rs-26025/v2

License: (c) (1) This work is licensed under a Creative Commons Attribution 4.0 International License. Read Full License 


\section{Abstract}

\section{Background}

Operation for the treatment of hepatocellular carcinoma (HCC) is limited. Recently, the possibility was advanced that operation (including surgery, transplantation, and ablation et, al) could be applied in HCC patients more widely. To address this issue, the trend in the use of operation and surgery for the treatment of HCC with time was analyzed. Additionally, whether patients gain a better survival benefit from surgery than other treatments was also evaluated.

\section{Methods}

Data from SEER registries were used to analyze the trends in the use operation and surgery for $\mathrm{HCC}$ and the survival benefits of these procedures. The study included patients between the ages of 35 and 84 years diagnosed as HCC between 2004 and $2015(n=64019)$. Propensity score matching (PSM) analysis was used to reduce selection bias.

\section{Results}

From 2004 to 2015, the rate of operation for HCC decreased in the localized group $(P<0.001)$, the regional and distant group $(P<0.001)$. Surgery rate in the localized, regional, and distant group also declined ( $P=0.016, P=0.009$, and $P=0.018$, respectively). Non-operation rate increased in the localized, regional, and distant group (all $P<0.001$ ). The median overall survival (mOS) of patients in the localized, regional group who underwent surgery was longer than that of patients with non-surgery operation and non-operation. Similar survival results were obtained in the analysis of patients with single tumor larger than $5 \mathrm{~cm}$ and 23 tumors larger than $3 \mathrm{~cm}$.

\section{Conclusion}

Although surgery rate declined from 2004 to 2015 in all HCC patients, it might be used more widely in patients with localized and regional tumors. And the treatment of surgery in patients with single tumor larger than $5 \mathrm{~cm}$ or patients with 2-3 tumors larger than $3 \mathrm{~cm}$ was worth trying.

\section{Background}

The incidence of hepatocellular carcinoma (HCC) becomes more frequent worldwide, with a $75 \%$ increase in the newly diagnosed cases from 1990 to 2015. It has been predicted that by 2030, HCC may become the third leading cause of cancer-related deaths in the USA [1]. The recommendations for the first-line treatment of early HCC include liver resection, transplantation or ablation. The first-line therapy for intermediate stages of HCC is transarterial chemoembolization (TACE), which can improve two-year survival outcomes. In advanced HCC with the tumor invading blood vessels and metastasizing to regional lymph nodes or distant organs, molecular-targeted drugs (sorafenib or lenvatinib) are 
recommended as the treatment of choice, which can extend the survival of the patients by up to 4 months $[1,2]$.

Drug-eluting beads, as a new embolic material, have been developed. The drug-eluting beads may reduce complications of the TACE and prolong the progress-free survival but not overall survival (OS) $[3,4]$.

However, some studies have documented that patients with intermediate HCC may have better survival after surgery than TACE [5-7]. A prospective randomized controlled trial (RCT) showed that the 1-, 2-, and 3-year OS rates of patients with resectable multiple HCC outside of Milan Criteria who received surgery were higher than that those of patients treated with TACE $(P<0.001)$ [5]. Another meta-analysis indicated that patients with intermediate-advanced $\mathrm{HCC}(\mathrm{BCLC} B / \mathrm{C})$ who were treated by surgery experienced greater survival benefit than those who received TACE therapy. In fact, all patients in the surgery group had longer OS than patients in the TACE group $(P<0.001)$ [8]. However, these studies had certain limitations. An insufficient number of patients were included in both investigations, and the meta-analysis included only one RCT, which might have led to a low level of evidence. The operation and surgery rate of patients are still unclear.

In view of these uncertainties, the present population-based study aimed to analyze the trends of operation (including surgery, transplantation, and ablation) and surgery, and to identify the optimal type of treatment for patients with different subgroups.

\section{Methods}

\section{Study Cohort}

Using Surveillance, Epidemiology, and End Results Program (SEER) 18 registries database, patients, 35-84 years old, diagnosed with HCC (International Classification of Diseases for Oncology, Third Edition (ICD0-3), histology code 8170-8175, site code C220 (liver)) between 2004 and 2015 were included. Patients for which the information on whether they received operation was not available, were excluded.

\section{Statistical analysis}

The patients' information was extracted from the SEER database using the SEER*Stat software (version 8.3.5). Temporal trend of the rates of operation, surgery and non-operation for the treatment of HCC was estimated using Cochran-Armitage test[9]. Median overall survival (mOS) was determined using KaplanMeier survival curves and was compared by log-rank test [10]. The prognostic factors for all patients and the surgery group were assessed by Cox proportional hazards model [11].

The characteristics of gender, ethnicity, age of diagnosis, year of diagnosis, tumor status, American joint committee on cancer (AJCC) stage, tumor size, tumor numbers, whether they received radiotherapy and whether they received chemotherapy were included into propensity score matching (PSM) analysis. The optimal caliper was set as 0.00001 and 9436 pairs of were matched by 1:1 nearest neighbor approach. All statistical tests were two-sided, and the a level of $P<0.05$ was considered statistically significant. 
SPSS v24.0 (IBM, Chicago, IL, USA) and SAS 9.4 statistical software (SAS Institute, Cary, NC, USA) were used to perform all statistical analyses.

\section{Definitions of tumor status}

Localized tumor is defined as the tumor is confined to the liver and does not invade regional lymph nodes or metastases to distant tissue. Regional tumor is defined as the tumor invades the regional tissue. Distant tumor is defined as the tumor metastases to distant organs or invades distant lymph nodes.

\section{Results}

A total of 64019 patients were included, including 15746 who received operation, and 48273 who did not receive operation.

For the survival analysis, patients with survival months code 0 (contact lost after diagnosis) and 9999 (unknown length of survival month) and patients with transplantation were excluded, leaving 52338 patients in this part of the study. After PSM, a total of 18872 patients were included into survival analysis. Among them, 9436 patients received operation treatment and 9436 patients received non-operation treatment. The baseline characteristics of patients before PSM and after PSM in the two group were compared (Table 1).

To determine whether patients could gain an additional survival benefit from surgery, the patients were divided into seven groups (group A-G) based on the BCLC stage A and B. Group A included patients with a single tumor size smaller than $5 \mathrm{~cm}$. Group $B$ included patients with a single tumor larger than $5 \mathrm{~cm}$ but no more than $7 \mathrm{~cm}$. Group $C$ included patients with a single tumor larger than $7 \mathrm{~cm}$ but no more than 9 $\mathrm{cm}$. Group D included patients with a single tumor larger than $9 \mathrm{~cm}$. Group E included patients with 2-3 tumors no more than $3 \mathrm{~cm}$. Group F included patients with 2-3 tumors larger than $3 \mathrm{~cm}$. Group $\mathrm{G}$ included patients with multiple tumors (>3 tumors) (Figure 1).

\section{Trends of operation and surgery on HCC}

The trends of operation rate increased in localized, regional and distant group (all $\mathrm{P}<0.001$ ). (Figure 2A). For surgery, the frequencies and trends in localized $(P=0.016)$, regional $(P=0.009)$, distant group $(P=0.018)$ declined with time (Figure 2B). For patients without operation treatment, the non-operation rate in the localized, regional and distant group increased (all $P<0.001$ ) (Figure $2 \mathrm{C}$ ).

\section{Median Overall Survival (mOS) in all patients and the subgroups}

After PSM, the mOS of patients in the surgery group ( 45 months, $95 \% \mathrm{Cl}: 42.4,47.6)$ was longer than that in the non-surgery operation group (32 months, $95 \% \mathrm{Cl} ; 31.1,32.9, P<0.001)$, which was longer than that in the non-operation group (12 months, $95 \% \mathrm{Cl}$ : 11.7,12.3), $P<0.001)$ (Figure 3$)$. The mOS of patients in localized group receiving surgery (59 months, $95 \% \mathrm{Cl}: 54.8,63.2)$ was longer than that of patients with non-surgery operation (38 months, $95 \% \mathrm{Cl}: 36.1,39.9, P<0.001$ ), which was longer than patients with non- 
operation (16 months, 95\% Cl: 15.3,16.7, P<0.001) (Figure 4A). Similar results were presented in regional, distant and unknown stage groups. In reginal group, the mOS of patients with surgery $(23$ months, $95 \% \mathrm{Cl}$ : $19.9,26.1)$ was longer than patients with non-surgery operation (22 months, $95 \% \mathrm{Cl}: 20.1,23.9, P=0.031)$, which was longer than patients in the non-operation (7 months, 95\% Cl: 6.4,7.6, $\mathrm{P}<0.001$ ) (Figure 4B). In distant group, the mOS of patients with non-surgery operation (11 months, $95 \% \mathrm{Cl}: 8.9,13.1)$ was longer than patients with non-operation (4 months, $95 \% \mathrm{Cl}$ : 3.5,4.5, $\mathrm{P}<0.001$ ) (Figure 4C). In the subgroups analysis, the patients in the group A who underwent surgery $(59$ months, $95 \% \mathrm{Cl}$ : 53,65$)$ had better survival than patients with non-surgery operation (36 months, $95 \% \mathrm{Cl}: 34.1,37.9, P<0.001$ ), which was longer than patients with non-operation (18 months, 17.1,18.9, $\mathrm{P}<0.001$ ) (Figure $5 A$ ). In group $B$, patients with surgery (43 months, 95\% Cl: 36,50) had also better survival than patients with non-surgery operation (21 months, $95 \% \mathrm{Cl}: 18,24, P<0.001)$, which was longer than patients with non-operation (9 months, $95 \% \mathrm{Cl}: 8,10$, $P<0.001)$ (Figure 5B). In group $C$, the mOS of patients with surgery (37 months, $95 \% \mathrm{Cl}$ : 29.9,44.1) was longer than patients with non-surgery operation (19 months, $95 \% \mathrm{Cl}: 14,24, \mathrm{P}<0.001)$, which was longer than patients with non-operation (6 months, $95 \% \mathrm{Cl}$ : 4.9,7.1, $P<0.001)$ (Figure 5C). In group D, the mOS of patients with surgery $(27$ months, $95 \% \mathrm{Cl}: 23.2,30.8)$ was longer than patients with non-surgery operation (12 months, $95 \% \mathrm{Cl}: 10.4,13.6, P<0.001)$, which was longer than patients in the non-operation (4 months, $95 \% \mathrm{Cl}$ : 3.7,4.3, $P<0.001$ ) (Figure 5D). In group $\mathrm{E}$, the mOS of patients with surgery (74 months, $95 \% \mathrm{Cl}$ : $56.6,91.4)$ was longer than patients with non-surgery operation (44 months, $95 \% \mathrm{Cl}: 36.9,51.1, P<0.001)$, which was longer than patients with non-operation (23 months, 95\% Cl: 20.2,25.8, $P<0.001)$ (Figure 5E). In group $F$, the mOS of patients with surgery $(47$ months, $95 \% \mathrm{Cl}$ : $39.1,54.9)$ was longer than patients with non-surgery operation (27 months, 95\%Cl: 23.6,30.4, $P<0.001$ ), which was longer than patients with nonoperation (10 months, $95 \% \mathrm{Cl}$ : 8.8,11.2, $P<0.001$ ) (Figure 5F). In group $\mathrm{G}$, the mOS of patients with surgery (67 months, $95 \% \mathrm{Cl}: 43.6,90.4)$ was longer than patients with non-surgery operation (22 months, $95 \% \mathrm{Cl}$ : $6.8,37.2, P=0.009)$. (Figure 5G).

\section{Predictors of OS in all patients and the operation group}

The multivariable regression analysis of all patients showed that operation was an independent favor factor for OS compared with non-operation (HR:2.412, 95\% Cl:1.2.329,2.499, $P<0.001$ ) for all patients after PSM. For patients with operation, the multivariable regression analysis showed that surgery was an independent favor factor for OS compared with patients with non-surgery operation (HR:1.556, $95 \% \mathrm{Cl}: 1.471,1.667, P<0.001$ ) (Table 2).

\section{Discussion}

The incidence of HCC in men and women increased from 2000 to 2013 and is predicted to increase until 2030 [12]. The main finding was that the trends of operation and surgery rate in the localized, regional, and distant group declined from 2004 to 2015. And the survival of patients with localized, regional, distant tumor, single tumor larger than $5 \mathrm{~cm}, 2-3$ tumors larger than $3 \mathrm{~cm}$ and multiple tumors (>3 tumors) benefits more from surgery than non-surgery operation. 
Since 1999, BCLC criteria have been used as a recommended guide for HCC treatment [13]. Surgery was advised for the treatment of HCC patients with BCLC stage A, who had good liver function and good physical condition. This recommendation limited the application of surgery in HCC treatment. For patients with BCLC stage B, TACE was recommended as the first-line treatment. HCC patients with BCLC stage $B$ who received TACE treatment had shorter mOS (16 to 42 months) than patients undergoing surgery (23 to 70 months) [6,14-17]. However, HCC patients with TACE have high recurrence due to incomplete embolization. [18.19]. Alternatively, the tumor can be removed completely by liver resection, reducing tumor recurrence and metastasis. It was suggested that patients with a single tumor larger than $5 \mathrm{~cm}$ should be classified as BCLC stage $A$ and receive a better survival benefit from liver resection [20]. In the present analysis, patients were divided into seven groups according to the size and number of tumor. The mOS of HCC patients undergoing surgery in the group A-G surgery was the longest. Although the results of the study showed that patients with single tumor larger than $5 \mathrm{~cm}$ could get more survival from surgery than patients with non-surgery operation. Thus far no RCT was performed for patients with single tumor larger than $5 \mathrm{~cm}$ that would focus on the effect of tumor size on the therapeutic efficacy of surgery or other types of operation, such as TACE. Therefore, the outcome of various treatments in patients with different tumor size was worth exploring by a large cohort study.

Multivariate analysis of patients with operation treatment also demonstrated that surgical treatment resulted in better mOS of the patients than non-surgery operation. In agreement with earlier publications, older patients, male patients, black patients, patients with larger tumor size, patients with tumor metastasis, single patients and patients with an early diagnosis of HCC had a worse prognosis. Several studies have shown that a higher number of tumors is associated with a worse prognosis of the HCC patients with radical treatment [21-23]. However, the current work documented that the presence of two tumors increased the mOS of patients. That might be the reason that patients with single tumor who were worse than patients with two tumors (AJCC stage III and IV: $18 \%$ vs $15 \%$ ).

Although this study provided encouraging results for patients treated with operation, in particular by surgery, the operation rate did not increase significantly with time, and the surgery rate decreased. These trends may be explained by the emergence of new drugs, such as sorafenib. The recommendation by the BCLC criteria that patients with BCLC stage $A$ and good liver function and physical condition should be treated by surgery might be another reason for the decline in the treatment of HCC by surgery. However, the results of the present analysis support the notion that patients can obtain a better survival benefit from surgery than from other types of operations.

The retrospective design of the present study constitutes its limitation since it might have led to a selection bias. However, the analysis was based on a large number of patients, which could increase the reliability of the results. The efficacy of surgery was compared only with non-surgery operation and nonoperation treatments, but comparisons with specific treatments were not performed. While this approach might not provide strong proof that surgery is the best treatment for patients with a localized tumor or regional metastases, the evidence was obtained that patients can receive a better survival benefit from operation, and surgery might be the best treatment choice. This study did not answer the question of 
whether patients with poor liver function and physical status should be treated surgically, but from the side, these patients could get better survival after undergoing operation. The conclusions reached here need to be confirmed by a large prospective cohort study.

\section{Conclusions}

In conclusion, this study provided a comprehensive analysis of the trends in the rate of operation and surgery for the treatment of HCC. Moreover, the efficacy of surgery was compared with the efficacy of non-surgery operation and non-operation in patients with different subgroups of HCC. The results indicated that patients with single tumor larger than $5 \mathrm{~cm}$ or patients with 2-3 tumors larger than $3 \mathrm{~cm}$ might get more survival from surgery than patients with non-surgery operations or non-operation.

\section{Declarations}

Ethics approval and consent to participate: The research do not need to be reviewed by the ethics committee because the data were from SEER database and the written informed consent was exempted. However, the data used in the research was permitted by the SEER database management department.

Consent to publish: Not applicable.

Available of data and materials: The data could be found in SEER database (https://seer.cancer.gov/data/).

Competing interests: The authors declare that they have no competing interests.

Funding: This study was supported by National Natural Science Foundation of China (No. 81873919). The funders had no role in the study design, data collection, data analysis, decision to publish.

\section{Authors' contributions:}

ZCS, FY conceived the study, analyzed the data. CL and CS performed the data collection and conducted the statistical analysis. CL, CS and ST writed the manuscript. All authors read and approved the final manuscript.

Acknowledgement: Not applicable.

Authors' information: $\mathrm{CL}, \mathrm{MD}^{\# 1,2,3} ; \mathrm{CS}, \mathrm{MD}^{\# 1,2} ; \mathrm{ST}, \mathrm{MD}^{1,2,3} ; \mathrm{YF}, \mathrm{MD}, \mathrm{PhD}^{\star 1,2} ; \mathrm{ZCS}, \mathrm{MD}, \mathrm{PhD}^{\star 1,2,3}$

${ }^{1}$ From the department of Radiology, Union Hospital, Tongji Medical College, Huazhong University of Science and Technology, Wuhan, 430022, China;

${ }^{2}$ From Hubei Province Key Laboratory of Molecular Imaging, Wuhan, 430022, China. 
${ }^{3}$ From the department of interventional radiology, Union Hospital, Tongji Medical College, Huazhong University of Science and Technology, Wuhan, 430022, China.

\section{References}

1. EASL Clinical Practice Guidelines: Management of hepatocellular carcinoma. J Hepato/2018, 69(1):182-236.

2. Bruix J, Sherman M: Management of hepatocellular carcinoma: an update. Hepatology 2011, 53(3):1020-1022.

3. Lammer J, Malagari K, Vogl T, Pilleul F, Denys A, Watkinson A, Pitton M, Sergent G, Pfammatter T, Terraz $S$ et al: Prospective randomized study of doxorubicin-eluting-bead embolization in the treatment of hepatocellular carcinoma: results of the PRECISION V study. Cardiovasc Intervent Radiol 2010, 33(1):41-52.

4. Malagari K, Pomoni M, Kelekis A, Pomoni A, Dourakis S, Spyridopoulos T, Moschouris H, Emmanouil E, Rizos S, Kelekis D: Prospective randomized comparison of chemoembolization with doxorubicineluting beads and bland embolization with BeadBlock for hepatocellular carcinoma. Cardiovasc Intervent Radiol 2010, 33(3):541-551.

5. Yin L, Li H, Li AJ, Lau WY, Pan ZY, Lai EC, Wu MC, Zhou WP: Partial hepatectomy vs. transcatheter arterial chemoembolization for resectable multiple hepatocellular carcinoma beyond Milan Criteria: a RCT. J Hepatol 2014, 61(1):82-88.

6. Tada T, Kumada T, Toyoda H, Tsuji K, Hiraoka A, Itobayashi E, Nouso K, Kariyama K, Ishikawa T, Hirooka $\mathrm{M}$ et al: Role of hepatic resection in patients with intermediate-stage hepatocellular carcinoma: A multicenter study from Japan. Cancer science 2017, 108(7):1414-1420.

7. Lee JM, Jang BK, Lee YJ, Choi WY, Choi SM, Chung WJ, Hwang JS, Kang KJ, Kim YH, Chauhan AK et al: Survival outcomes of hepatic resection compared with transarterial chemoembolization or sorafenib for hepatocellular carcinoma with portal vein tumor thrombosis. Clinical and molecular hepatology 2016, 22(1):160-167.

8. Hyun MH, Lee YS, Kim JH, Lee CU, Jung YK, Seo YS, Yim HJ, Yeon JE, Byun KS: Hepatic resection compared to chemoembolization in intermediate- to advanced-stage hepatocellular carcinoma: A meta-analysis of high-quality studies. Hepatology 2018, 68(3):977-993.

9. Buonaccorsi JP, Laake P, Veierod MB: On the power of the Cochran-Armitage test for trend in the presence of misclassification. Stat Methods Med Res 2014, 23(3):218-243.

10. van Walraven C, McAlister FA: Competing risk bias was common in Kaplan-Meier risk estimates published in prominent medical journals. J Clin Epidemiol 2016, 69:170-173 e178.

11. Staley JR, Jones E, Kaptoge S, Butterworth AS, Sweeting MJ, Wood AM, Howson JMM: A comparison of Cox and logistic regression for use in genome-wide association studies of cohort and case-cohort design. Eur J Hum Genet 2017, 25(7):854-862. 
12. Petrick JL, Kelly SP, Altekruse SF, McGlynn KA, Rosenberg PS: Future of Hepatocellular Carcinoma Incidence in the United States Forecast Through 2030. J Clin Oncol 2016, 34(15):1787-1794.

13. Llovet JM, Bru C, Bruix J: Prognosis of hepatocellular carcinoma: the BCLC staging classification. Semin Liver Dis 1999, 19(3):329-338.

14. Kim JY, Sinn DH, Gwak GY, Choi GS, Saleh AM, Joh JW, Cho SK, Shin SW, Carriere KC, Ahn JH et al: Transarterial chemoembolization versus resection for intermediate-stage (BCLC B) hepatocellular carcinoma. Clinical and molecular hepatology 2016, 22(2):250-258.

15. Lin C-L, Lin C-K, Lin T-J, Lee H-C, Chen K-Y, Liao L-Y, Ting C-T, Wang C-K: Comparison of surgical resection and transarterial chemoembolization for patients with intermediate stage hepatocellular carcinoma. Journal of Cancer Research and Practice 2016, 3(2):34-38.

16. Luo J, Peng ZW, Guo RP, Zhang YQ, Li JQ, Chen MS, Shi M: Hepatic resection versus transarterial lipiodol chemoembolization as the initial treatment for large, multiple, and resectable hepatocellular carcinomas: a prospective nonrandomized analysis. Radiology 2011, 259(1):286-295.

17. Lin CT, Hsu KF, Chen TW, Yu JC, Chan DC, Yu CY, Hsieh TY, Fan HL, Kuo SM, Chung KP et al: Comparing hepatic resection and transarterial chemoembolization for Barcelona Clinic Liver Cancer (BCLC) stage B hepatocellular carcinoma: change for treatment of choice? World journal of surgery 2010, 34(9):2155-2161.

18. Zhang J, Zhang Q, Lou Y, Fu Q, Chen Q, Wei T, Yang J, Tang J, Wang J, Chen Y et al: Hypoxiainducible factor-1alpha/interleukin-1beta signaling enhances hepatoma epithelial-mesenchymal transition through macrophages in a hypoxic-inflammatory microenvironment. Hepatology 2018, 67(5):1872-1889.

19. Dang CV, Semenza GL: Oncogenic alterations of metabolism. Trends Biochem Sci 1999, 24(2):68-72.

20. Forner A, Gilabert M, Bruix J, Raoul JL: Treatment of intermediate-stage hepatocellular carcinoma. Nature reviews Clinical oncology 2014, 11(9):525-535.

21. Toyoda H, Kumada T, Kaneoka Y, Osaki Y, Kimura T, Arimoto A, Oka H, Yamazaki O, Manabe T, Urano $\mathrm{F}$ et al: Prognostic value of pretreatment levels of tumor markers for hepatocellular carcinoma on survival after curative treatment of patients with HCC. J Hepatol 2008, 49(2):223-232.

22. Toyoda H, Kumada T, Tada T, Niinomi T, Ito T, Kaneoka Y, Maeda A: Prognostic significance of a combination of pre- and post-treatment tumor markers for hepatocellular carcinoma curatively treated with hepatectomy. J Hepatol 2012, 57(6):1251-1257.

23. Xu XF, Xing H, Han J, Li ZL, Lau WY, Zhou YH, Gu WM, Wang H, Chen TH, Zeng YY et al: Risk Factors, Patterns, and Outcomes of Late Recurrence After Liver Resection for Hepatocellular Carcinoma: A Multicenter Study From China. JAMA surgery 2019, 154(3):209-217.

\section{Tables}

Table 1: Characteristics of patients before PSM and after PSM. 


\begin{tabular}{|c|c|c|c|c|c|c|}
\hline \multirow[t]{2}{*}{ Characteristics } & \multicolumn{3}{|l|}{$\begin{array}{l}\text { Before PSM } \\
(\mathrm{N}=52338)\end{array}$} & \multicolumn{3}{|l|}{ After PSM } \\
\hline & $\begin{array}{l}\text { Operation } \\
(\mathrm{N}=12348)\end{array}$ & $\begin{array}{l}\text { Non-operation } \\
(\mathrm{N}=39990)\end{array}$ & $\begin{array}{l}\mathrm{P} \\
\text { value }\end{array}$ & $\begin{array}{l}\text { Operation } \\
(\mathrm{N}=9436)\end{array}$ & $\begin{array}{l}\text { Non- } \\
\text { operation } \\
(\mathrm{N}=9436)\end{array}$ & $\begin{array}{l}\mathrm{P} \\
\text { value }\end{array}$ \\
\hline Gender & & & $<0.001$ & & & 0.729 \\
\hline Male & 9180 & 31292 & & 7272 & 7292 & \\
\hline Female & 3168 & 8698 & & 2164 & 2144 & \\
\hline Ethnicity & & & $<0.001$ & & & 0.633 \\
\hline White & 7888 & 27555 & & 6657 & 6604 & \\
\hline Black & 1452 & 5771 & & 1071 & 1108 & \\
\hline Other & 3008 & 6664 & & 1708 & 1724 & \\
\hline $\begin{array}{l}\text { Age of } \\
\text { diagnosis }\end{array}$ & & & $<0.001$ & & & 0.808 \\
\hline $35-44$ & 340 & 794 & & 162 & 146 & \\
\hline $45-54$ & 1905 & 6873 & & 1499 & 1484 & \\
\hline $55-64$ & 4765 & 15334 & & 3740 & 3751 & \\
\hline$\geq 65$ & 5338 & 16989 & & 4035 & 4055 & \\
\hline $\begin{array}{l}\text { Year of } \\
\text { diagnosis }\end{array}$ & & & $<0.001$ & & & 0.942 \\
\hline $2004-2007$ & 3406 & 9217 & & 2581 & 2560 & \\
\hline 2008-2011 & 3869 & 13689 & & 2949 & 2961 & \\
\hline $2012-2015$ & 5073 & 17084 & & 3906 & 3915 & \\
\hline Tumor status & & & $<0.001$ & & & 0.981 \\
\hline Localized & 9450 & 17475 & & 6902 & 6907 & \\
\hline Regional & 2225 & 12126 & & 1946 & 1945 & \\
\hline Distant & 360 & 6558 & & 303 & 294 & \\
\hline Unknown & 313 & 3831 & & 285 & 290 & \\
\hline AJCC stage & & & $<0.001$ & & & 0.980 \\
\hline I & 6808 & 11220 & & 4959 & 4973 & \\
\hline II & 2900 & 6227 & & 2188 & 2167 & \\
\hline III & 1604 & 9033 & & 1384 & 1371 & \\
\hline
\end{tabular}




\begin{tabular}{|c|c|c|c|c|c|c|}
\hline IV & 297 & 6313 & & 271 & 274 & \\
\hline Unknown & 739 & 7197 & & 634 & 651 & \\
\hline Tumor size & & & $<0.001$ & & & 0.983 \\
\hline$\leq 5 \mathrm{~cm}$ & 8062 & 16535 & & 6110 & 6116 & \\
\hline $5-7 \mathrm{~cm}$ & 1455 & 5209 & & 1085 & 1062 & \\
\hline 7-9 cm & 717 & 3376 & & 519 & 529 & \\
\hline$>9 \mathrm{~cm}$ & 1336 & 6038 & & 1018 & 1017 & \\
\hline Unknown & 778 & 8832 & & 704 & 712 & \\
\hline Tumor number & & & & & & 0.704 \\
\hline 1 & 9807 & 34191 & $<0.001$ & 7994 & 7978 & \\
\hline 2 & 2042 & 4879 & & 1248 & 1268 & \\
\hline 3 & 384 & 760 & & 163 & 167 & \\
\hline$>3$ & 115 & 160 & & 31 & 23 & \\
\hline Radiotherapy & & & $<0.001$ & & & 0.925 \\
\hline Yes & 385 & 3784 & & 284 & 278 & \\
\hline No & 11940 & 36093 & & 9147 & 9152 & \\
\hline Unknown & 23 & 113 & & 5 & 6 & \\
\hline Chemotherapy & & & $<0.001$ & & & 0.668 \\
\hline Yes & 3540 & 19173 & & 3282 & 3254 & \\
\hline No & 8808 & 20817 & & 6154 & 6182 & \\
\hline
\end{tabular}

Table 2: Multivariate regression analysis for overall survival of all patients and patients with operation after PSM. 
Characteristics

Characteristics

\section{Gender}

Male

Female

Ethnicity

White

Black

Other

Age of diagnosis

$35-44$

45-54

55-64

$\geq 65$

\section{Year of diagnosis}

2004-2007

2008-2011

2012-2015

\section{Tumor status}

Localized

Regional

Distant

Unknown

\section{AJCC stage}

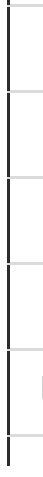

I

III

IV

Unknown
All patients

$\mathrm{HR}(95 \% \mathrm{Cl})$
Patients in the operation group

$P$ value $H R(95 \% \mathrm{Cl})$
P Value

Reference

$0.924(0.867,0.985)$

0.015
Reference

$0.947(0.908,0.987) \quad 0.010$
Reference

$1.129(1.040,1.226)$

$0.747(0.696,0.802)$
0.004 $<0.001$

$\begin{array}{llll}1.077(1.021,1.136) & 0.006 & 1.129(1.040,1.226) & 0.004 \\ 0.769(0.734,0.833) & <0.001 & 0.747(0.696,0.802) & <0.001\end{array}$

Reference

Reference

$1.135(0.924,1.393)$

0.228

0.256

$1.158(1.009,1.330) \quad 0.037$

$1.123(0.919,1.372)$

0.001

$1.418(1.235,1.627) \quad<0.001 \quad 1.413(1.157,1.725)$

Reference

Reference

$0.833(0.783,0.886)$

$<0.001$

$0.869(0.834,0.906) \quad<0.001$

$0.689(0.643,0.739)$

$<0.001$

Reference

Reference

$1.326(1.259,1.397) \quad<0.001$

$1.291(1.194,1.397)$

$1.620(1.113,2.358)$

$1.055(0.870,1.279)$
$<0.001$

0.012

0.585

\begin{tabular}{llll}
$1.785(1.337,2.384)$ & $<0.001$ & $1.620(1.113,2.358)$ & 0.012 \\
\hline $0.939(0.828,1.064)$ & 0.324 & $1.055(0.870,1.279)$ & 0.585
\end{tabular}

Reference

$1.234(1.186,1.303) \quad<0.001$

$1.479(1.383,1.581) \quad<0.001$

$1.470(1.085,1.993) \quad 0.013$

$1.377(1.257,1.508) \quad<0.001$
Reference

$1.265(1.178,1.360)$

$1.623(1.468,1.794)$

$1.742(1.168,2.597)$

$1.223(1.061,1.409)$
$<0.001$

$<0.001$

0.006

0.005 


\begin{tabular}{|c|c|c|c|c|}
\hline \multicolumn{5}{|l|}{ Tumor size } \\
\hline$\leq 5 \mathrm{~cm}$ & Reference & & Reference & \\
\hline $5-7 \mathrm{~cm}$ & $1.403(1.322,1.488)$ & $<0.001$ & $1.211(1.106,1.327)$ & $<0.001$ \\
\hline $7-9 \mathrm{~cm}$ & $1.535(1.421,1.658)$ & $<0.001$ & $1.285(1.140,1.449)$ & $<0.001$ \\
\hline$>9 \mathrm{~cm}$ & $1.889(1.775,2.009)$ & $<0.001$ & $1.612(1.465,1.774)$ & $<0.001$ \\
\hline Unknown & $1.430(1.329,1.538)$ & $<0.001$ & $1.223(1.093,1.369)$ & $<0.001$ \\
\hline \multicolumn{5}{|l|}{ Tumor number } \\
\hline 1 & Reference & & Reference & \\
\hline 2 & $0.898(0.854,0.945)$ & $<0.001$ & $0.913(0.844,0.987)$ & 0.021 \\
\hline 3 & $0.882(0.774,1.005)$ & 0.059 & $0.928(0.759,1.136)$ & 0.469 \\
\hline$>3$ & $0.879(0.647,1.196)$ & 0.413 & $0.681(0.594,1.405)$ & 0.681 \\
\hline \multicolumn{5}{|l|}{ Radiotherapy } \\
\hline Yes & Reference & & Reference & \\
\hline No & $1.112(1.006,1.229)$ & 0.038 & $0.812(0.701,0.940)$ & 0.005 \\
\hline Unknown & $1.073(0.532,2.165)$ & 0.843 & $0.530(0.169,1.668)$ & 0.278 \\
\hline \multicolumn{5}{|l|}{ Chemotherapy } \\
\hline Yes & Reference & & Reference & \\
\hline No & $1.393(1.343,1.445)$ & $<0.001$ & $0.968(0.915,1.024)$ & 0.252 \\
\hline Treatment & & & - & - \\
\hline Operation & Reference & & - & - \\
\hline Non-operation & $2.412(2.329,2.499)$ & $<0.001$ & - & - \\
\hline Treatment & - & - & & \\
\hline Surgery & - & - & Reference & \\
\hline Non-surgery operation & - & - & $1.556(1.471,1.667)$ & $<0.001$ \\
\hline
\end{tabular}

\section{Figures}




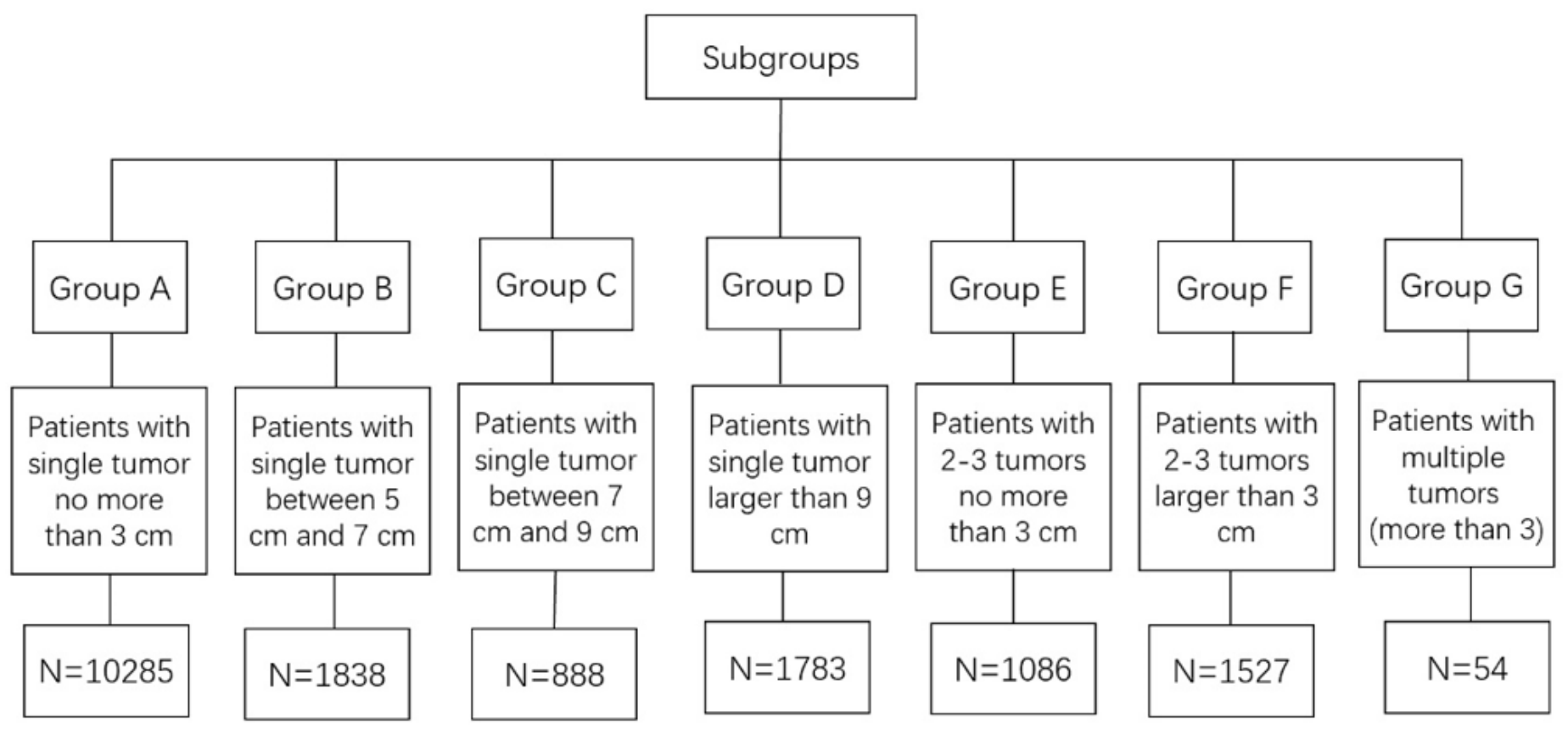

Figure 1

The chart of subgroups classification.
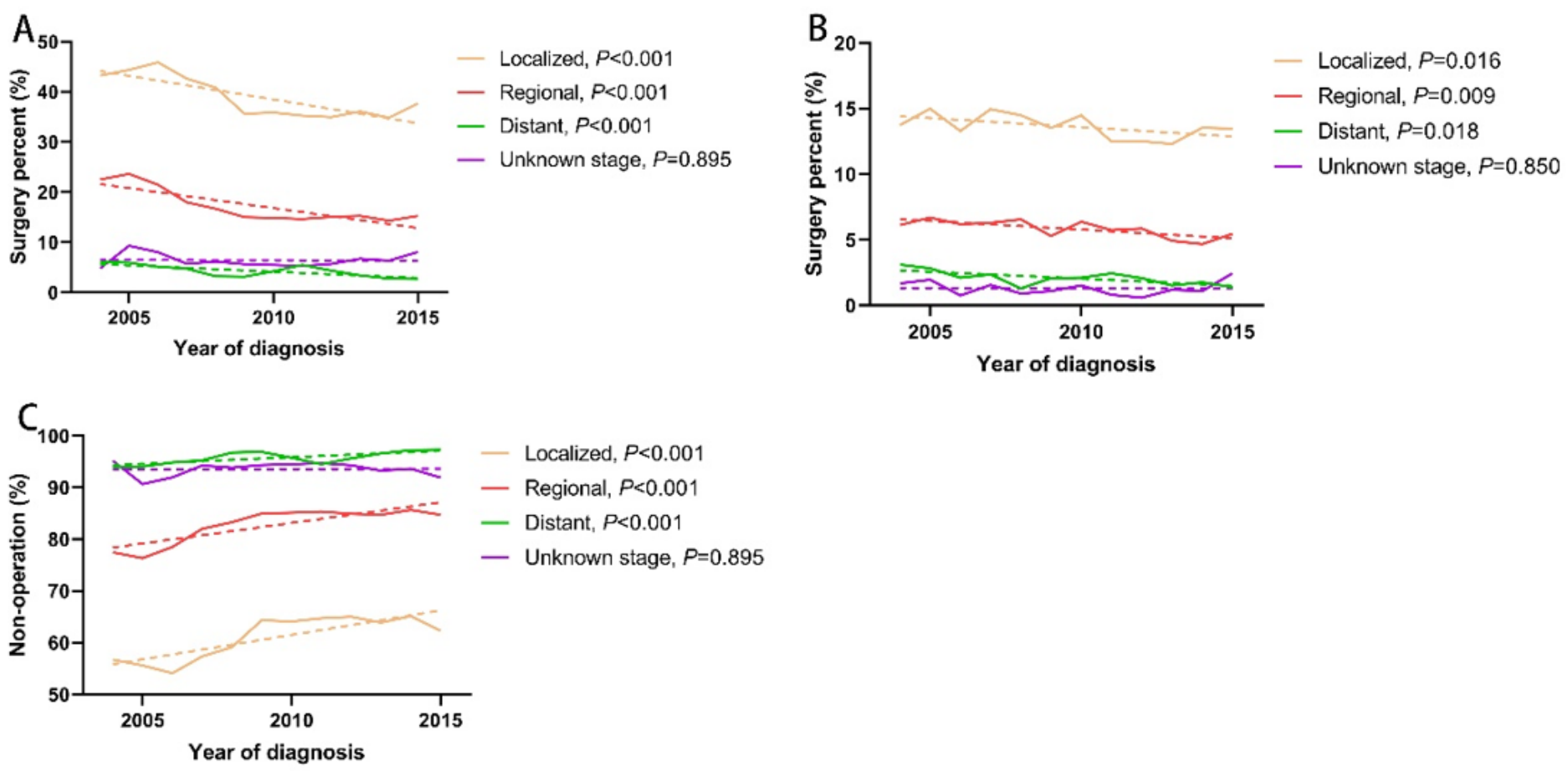

Figure 2

The trends of operation rate (A), surgery rate (B), and non-operation rate (C)in localized group, regional group, distant group and unknown/unstaged group from 1998 to 2015. 


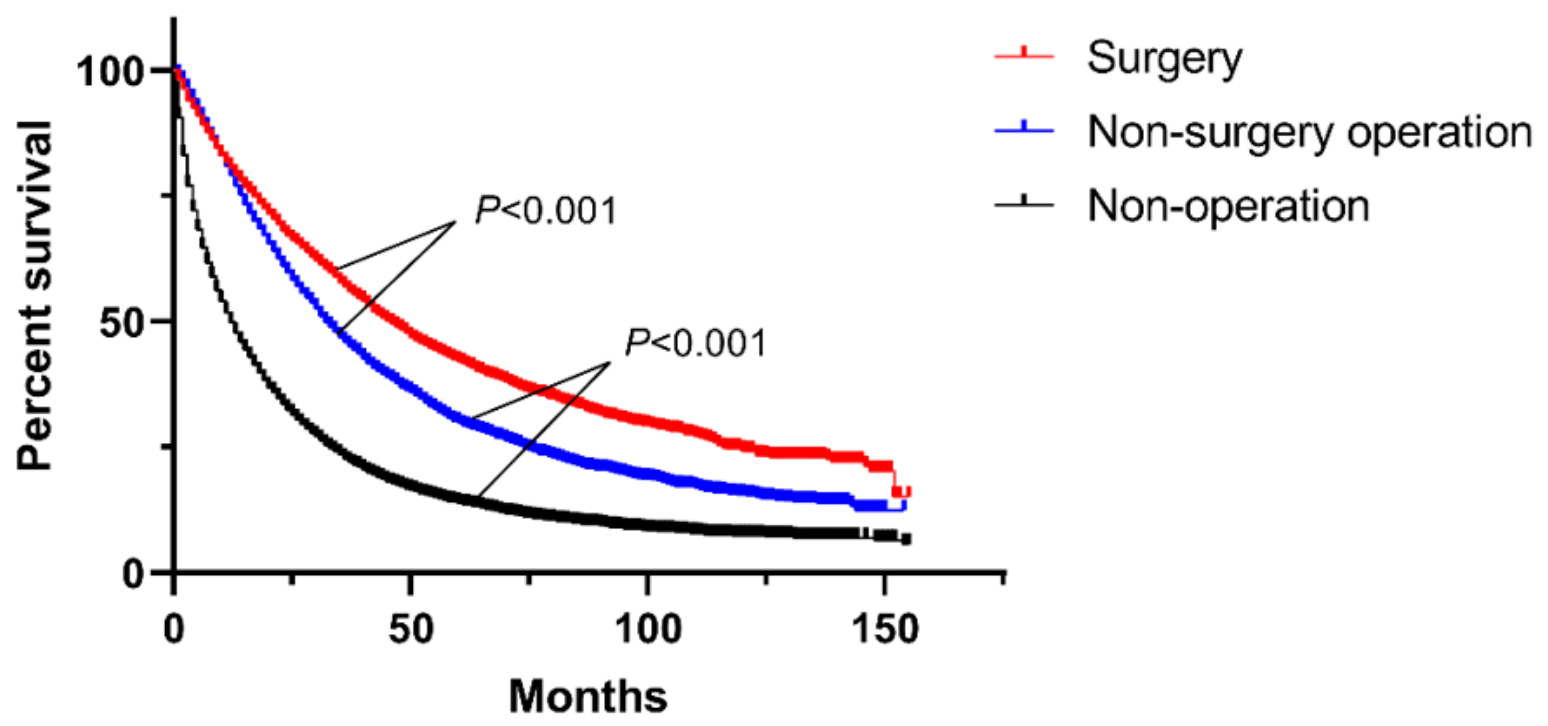

No. at risk

$\begin{array}{llllllll}\text { Surgery } & 3771 & 2144 & 1126 & 596 & 276 & 110 & 10\end{array}$

$\begin{array}{llllllll}\text { Non-surgery operation } & 5665 & 2842 & 1219 & 557 & 271 & 90 & 4\end{array}$

$\begin{array}{llllllll}\text { Non-operation } & 9436 & 2599 & 960 & 418 & 190 & 82 & 14\end{array}$

-operation after PSM.

Figure 3

Kaplan-Meier curve of all patients with surgery or non-surgery operation or non

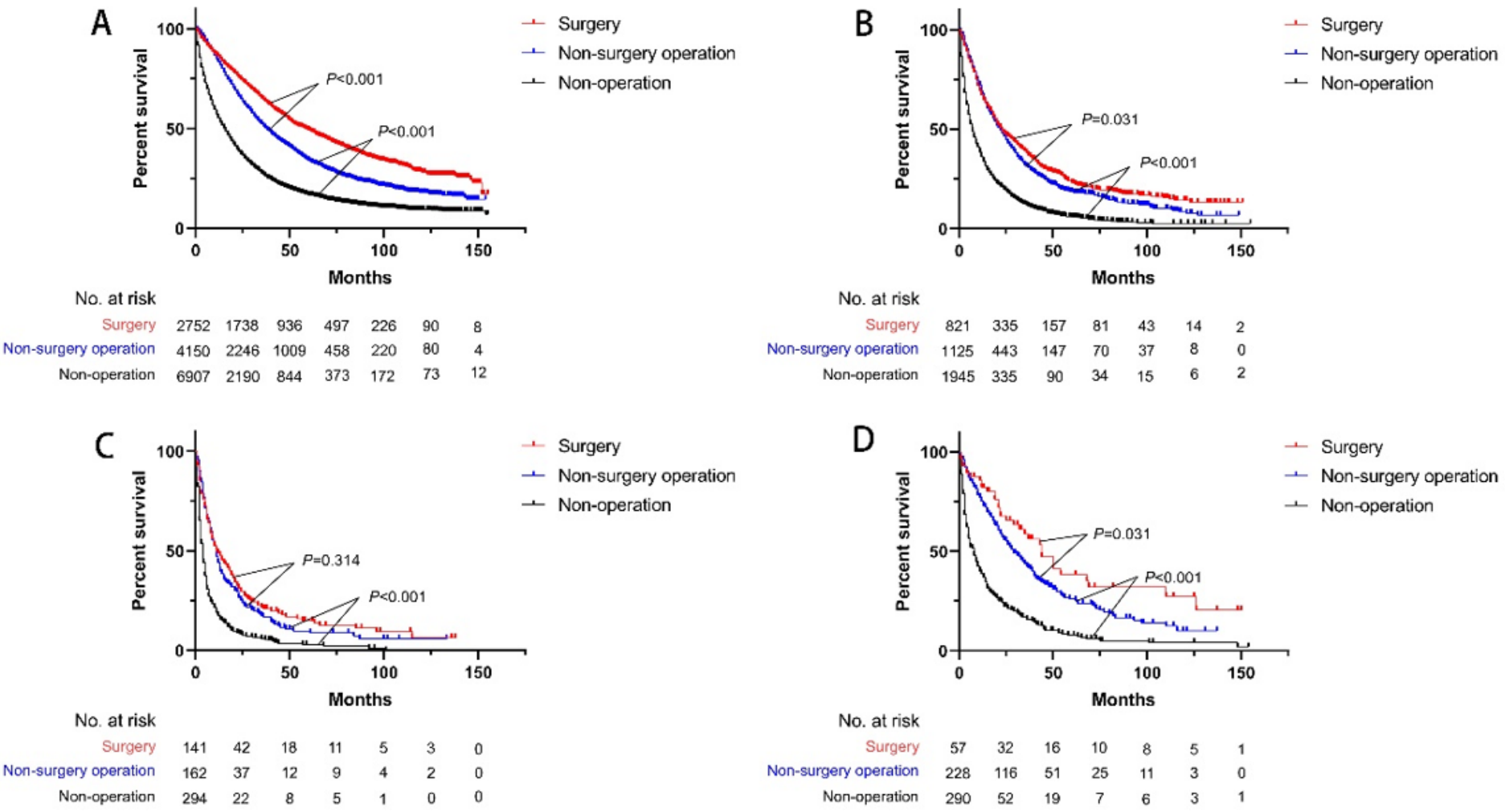


Figure 4

Kaplan-Meirer curve of patients: (A) Kaplan-Meier curve of patients in the localized group; (B) KaplanMeier curve of patients in the regional group; (C) Kaplan-Meier curve of patients in the distant group; (D) Kaplan-Meier curve of patients in the unknown stage group.

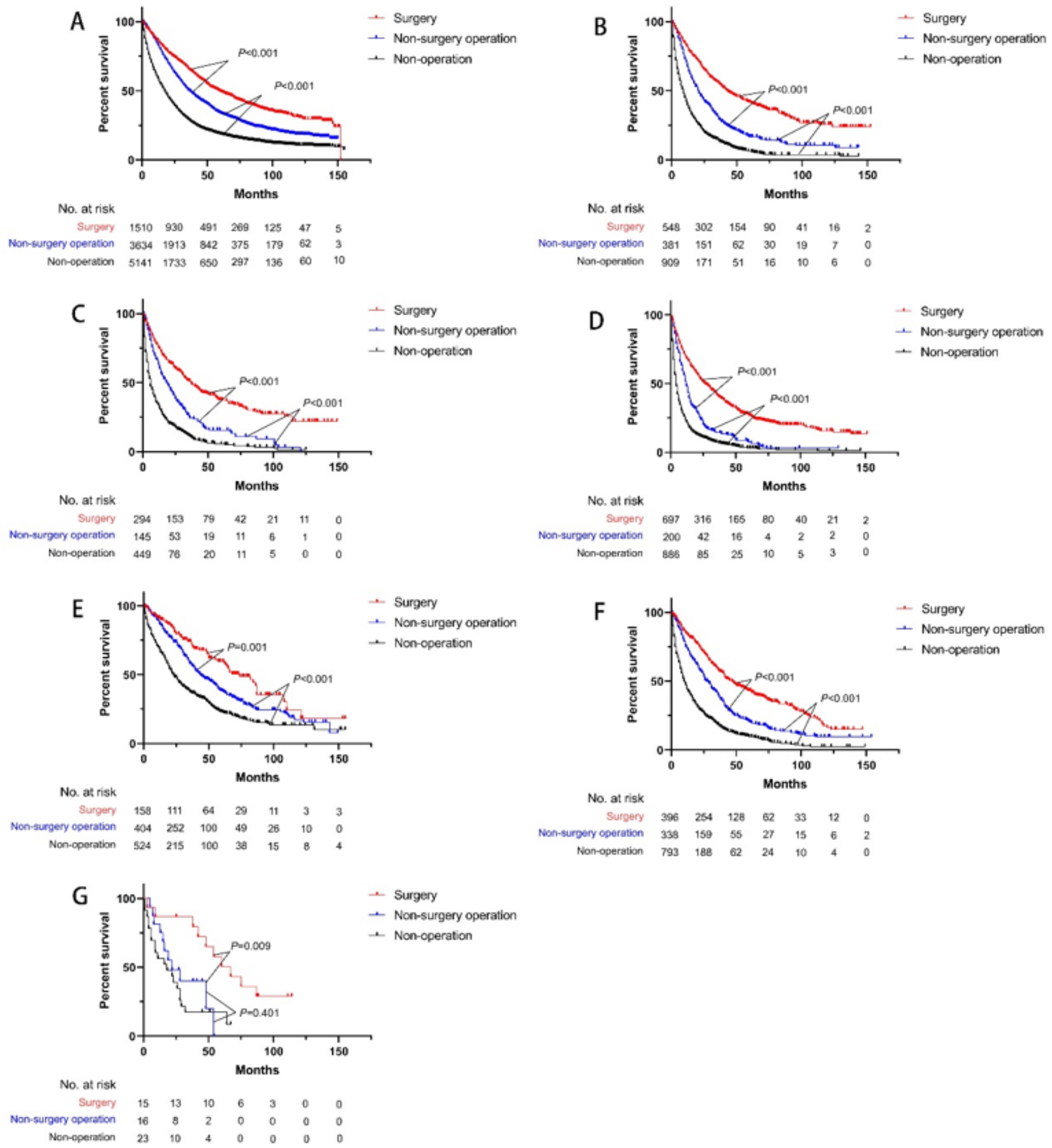

Figure 5 
Kaplan-Meier of patients in the subgroups: (A) Kaplan-Meier curve of patients with single tumor no more than $5 \mathrm{~cm}$; (B) Kaplan-Meier curve of patients with single tumor larger than $5 \mathrm{~cm}$ but no more than $7 \mathrm{~cm}$; (C) Kaplan-Meier curve of patients with single tumor larger than $7 \mathrm{~cm}$ but no more than $9 \mathrm{~cm}$; (D) KaplanMeier curve of patients with single tumor larger than $9 \mathrm{~cm}$; $(\mathrm{E})$ Kaplan-Meier curve of patients with 2-3 tumors no more than $3 \mathrm{~cm}$; (F) Kaplan-Meier curve of patients with 2-3 tumors larger than $3 \mathrm{~cm}$; (G) Kaplan-Meier curve of patients with multiple tumors ( $>3$ tumors).

\section{Supplementary Files}

This is a list of supplementary files associated with this preprint. Click to download.

- AdditionalFileFigures.docx

- STROBEchecklist.docx 